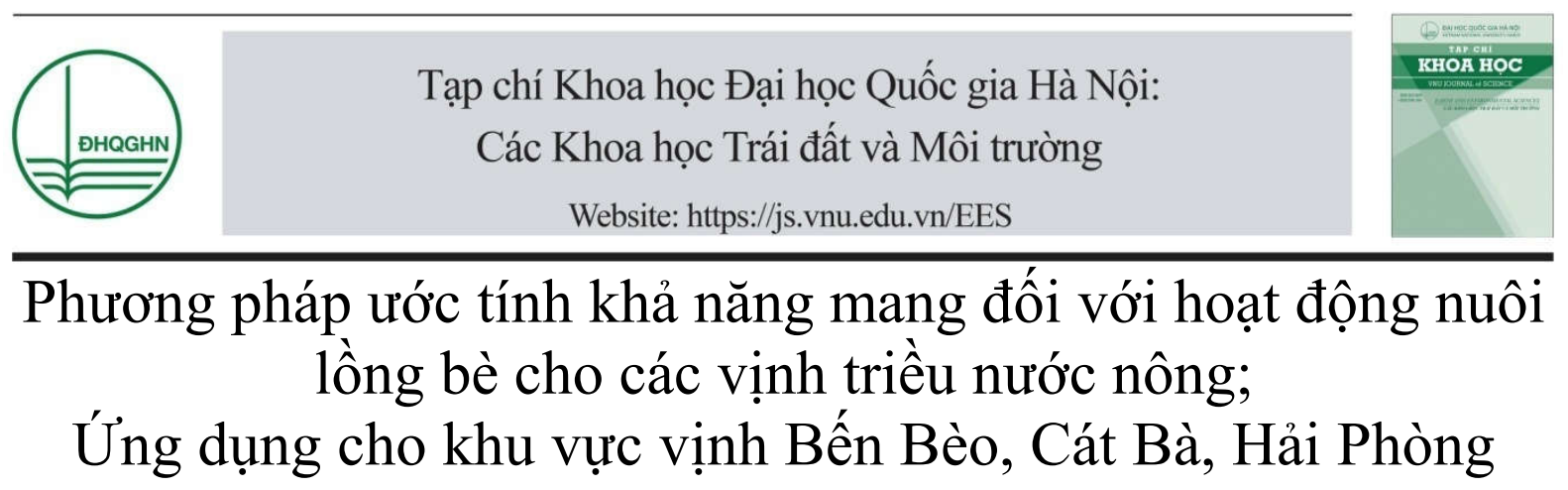

\author{
Trịnh Thị Lê Hà* \\ Khoa Khi tuợng Thủy văn và Hải dương học, Truờng Đại học Khoa học Tự nhiên, \\ Đại học Quốc gia Hà Nội, 334 Nguyễn Trãi, Thanh Xuân, Hà Nội \\ Nhận ngày 30 tháng 11 năm 2018 \\ Chỉnh sửa ngày 12 tháng 12 năm 2018; Chấp nhận đăng ngày 25 tháng 12 năm 2018
}

\begin{abstract}
Tóm tắt: Đánh giá sức tải môi trường đối với hoạt động nuôi lồng bè cho các vịnh nước nông ven bờ là hoạt động hết sức cần thiết. Hoạt động này không những hỗ trợ cho công tác quy hoạch mà còn đảm bảo tính cân bằng tự nhiên của các hệ sinh thái như vũng vịnh. Phương pháp ước tính khả năng mang dựa trên nguồn dinh dưỡng phát thải từ hoạt động nuôi, tỉ lệ trao đổi nước và nguy cơ bùng phát của tảo là công cụ đánh giá phù hợp cho các vịnh triều nhỏ đang chịu ảnh hưởng của hoạt động nuôi trồng như Bến Bèo. Các kết quả ước tính cho thấy, lượng phát thải dinh dưỡng từ hoạt động nuôi năm 2017 có dấu hiệu vượt quá khả năng mang của khu vực khi tỉ lệ trao đổi nước ở mức yếu và trung bình. Lượng phát thải dinh dưỡng từ hoạt động nuôi năm 2008 luôn vượt quá mức chịu tải của khu vực. Lượng phát thải từ hoạt động nuôi theo dự kiến trong quy hoạch luôn ở mức an toàn. Tuy nhiên, khi triều kém và nước đứng, khả năng mang trong mọi trường hợp đều có thể bị vượt quá.
\end{abstract}

Từ khóa: Khả năng mang, dinh dưỡng, Chl-a, hoạt động nuôi.

\section{Mở đầu}

Các vịnh triều nước nông là những vịnh chịu ảnh hưởng mạnh của thủy triều và có độ sâu nước không quá lớn thường dưới $10 \mathrm{~m}$, do vậy ít có sự phân tầng. Điều này cho phép có thể sử dụng giả thiết nước trong vịnh có sự xáo trộn tốt, đặc biệt là những vịnh có diện tích nhỏ. Thông thường đây đều là những vịnh tương đối

\footnotetext{
* Tác giả liên hệ. ĐT.: 84-988243503.

Email: hat1@vnu.edu.vn

https://doi.org/10.25073/2588-1094/vnuees.4339
}

kín, do vậy chúng thường được sử dụng làm nơi trú ẩn cho tầu bè và là nơi nuôi trồng thủy hải sản theo phương thức lồng bè. Tuy nhiên cũng vì có cấu trúc đặc trưng là tương đối kín nên các vịnh rất nhạy cảm đối với các vấn đề môi trường Việc ước tính được khả năng mang của vịnh đối với các hoạt động phát triển kinh tế, chẳng hạn như nuôi trồng thủy sản có thể xem là bước khởi đầu cho việc quản lý các vịnh theo mục tiêu phát triển bền vững.

Bến Bèo là một vịnh nhỏ (khoảng 600ha) nằm ven đảo Cát Bà có mức độ tương đối kín do sự che chắn của các đảo nhỏ (hình 1 ). Theo 
kết quả quan trắc thường kỳ hàng năm của Trung tâm quan trắc môi trường Biển (Viện Hải sản), độ sâu lớn nhất của vịnh đo được là khoảng $8 \mathrm{~m}$ [1], do vậy đây có thể coi là một vịnh nông. Vì nằm trong khu vực đảo có cấu tạo địa chất là Đá vôi nên lượng sông suối ở đây ít phát triển, lượng nước ngọt đổ vào vịnh không đáng kể dẫn đển ảnh hưởng chính đến khối nước trong vịnh là thủy triều [2]. Hiện tại, vịnh Bến Bèo đang là khu vực có mức độ tập trung nuôi cá lồng bè cao nhất đảo Cát Bà. Tại thời điểm khảo sát vào tháng $8 / 2017$ số lượng bè nuôi tại đây là khoảng 204 bè với 4.691 ô lồng (kích thước $3 \times 3 \times 3 \mathrm{~m}$ hoặc $3 \times 4 \times 3 \mathrm{~m}$ ), loài cá được nuôi phổ biến nhất là các loại cá song thuộc họ cá mú. Tính đến năm 2017, hoạt động nuôi trồng trong khu vực này đã diễn ra gần 20 năm, nhưng chỉ có một năm xảy ra hiện tượng cá nuôi chết hàng loạt là năm 2008. Đây cũng là năm mật độ lồng nuôi đạt số lượng lớn tới 6.478 lồng [3]. Theo quy hoạch đến năm 2020 của thành phố Hải Phòng, tổng số lượng bè nuôi sẽ được giảm xuống còn 170 bè, tương đương 2.720 ô lồng có kích thước $3 \times 3 \times 3 \mathrm{~m}$; $3 \times 4 \times 3 \mathrm{~m}$ hoặc $4 \times 4 \times 4 \mathrm{~m}$ và diện tích mặt nước được sử dụng cho hoạt động nuôi chiếm khoảng 295ha [4].

\section{Phương pháp ước tính}

\section{1. Ước tính khả năng mang đối với hoạt động nuôi trồng của một khối nước}

Khả năng mang của một khối nước đối với hoạt động nuôi trồng có thể được định nghĩa như là số lượng cá nuôi lớn nhất mà khối nước đó có thể đảm bảo an toàn cho hoạt động nuôi. Nếu trong một khối nước chỉ tồn tại duy nhất các hoạt động nuôi thì diện tích mặt nước dành cho nuôi trồng sẽ cho biết giới hạn trên của giá trị này. Tuy nhiên, giới hạn này có thể lớn hơn nhiều khả năng mang của khối nước bởi giá trị thực còn phụ thuộc vào nhiều yếu tố.

Một trong những yếu tố điển hình có ảnh hưởng lớn đến số lượng cá nuôi đó chính là nồng độ oxy hòa tan. Giá trị nồng độ này không được phép thấp hơn một giá trị tới hạn nào đó để đảm bảo nhu cầu oxy cho cá trong quá trình hô hấp. Về nguyên lý, trong những ngày trời quang, cá nuôi với mật độ cao sẽ là sinh vật tiêu thụ oxy nhiều nhất, nhưng vào những ngày âm $\mathrm{u}$, thực vật phù du (TVPD) với sinh khối lớn mới là loài sử dụng nhiều oxy nhất. Vì vậy, để đảm bảo nồng độ oxy cho cá thì sinh khối TVPD trong khối nước không được phép tăng trưởng quá mạnh. Sự tăng trưởng này phụ thuộc rất nhiều vào nồng độ dinh dưỡng trong nước. Trong khi, các hoạt động nuôi lại chính là nguồn cung cấp dinh dưỡng dồi dào nhất. Để cân bằng mối quan hệ này, bản thân số lượng cá nuôi cũng phải được điều chỉnh ở mức phù hợp.

Với lập luận đó, Legovic và các cộng sự (2008) đã đề xuất phương pháp ước tính khả năng mang của một khối nước dựa vào sự tăng trưởng của TVPD trên cở sở hàm lượng dinh dưỡng được đưa vào. Theo đó sự biến thiên của sinh khối TVPD trong khối nước dựa vào hàm lượng dinh dưỡng được mô phỏng như sau [5]:

Xét một khối nước (có sự xáo trộn tốt) có hàm lượng dinh dưỡng tự nhiên $\mathrm{S}$, hàm lượng dinh dưỡng nằm trong sinh khối TVPD của khối nước là $\mathrm{X}$. Hàm lượng dinh dưỡng được đưa vào là $\mathrm{Q} \times \mathrm{I}(\mathrm{Q}$ là lưu lượng nước vào và $\mathrm{I}$ là nồng độ dinh dưỡng trung bình được đưa vào). Do đó, sự biến đổi của hàm lượng dinh dưỡng theo tỉ lệ thể tích là $\mathrm{Q} \times \mathrm{I} / \mathrm{V}=\mathrm{D} \times \mathrm{I}$. Trong đó, $\mathrm{V}$ là thể tích của khối nước, $\mathrm{D}$ là tỉ lệ trao đổi nước (với giả thiết dòng ra bằng dòng vào). Phụ thuộc vào sự trao đổi nước, hàm lượng dinh dưỡng của khối nước bị mất theo dòng ra là $\mathrm{D} \times \mathrm{S}$ và hàm lượng dinh dưỡng bị mất do TVPD sử dụng là $\mathrm{u} \times \mathrm{X}$. Tuy nhiên, TVPD cũng bị rửa trôi ra khỏi khối nước theo dòng ra và lượng này tương đương với $\mathrm{D} \times \mathrm{X}$. Theo đó sự biến thiên của hàm lượng dinh dưỡng trong khối nước $(\mathrm{dS} / \mathrm{dt})$ và trong sinh khối thực vật phù $\mathrm{du}(\mathrm{dX} / \mathrm{dt})$ có thể được biểu diễn như sau:

$$
\begin{aligned}
& d S / d t=D(I-S)-u X \\
& d X / d t=(u-D) X
\end{aligned}
$$

Trong đó, $u$ là tốc độc tăng trưởng riêng của TVPD đồng thời cũng là hệ số sử dụng dinh dưỡng Michaelis-Menten-Monod và $\mathrm{u}=$ 
$\mathrm{V}_{\max } \mathrm{S} /(\mathrm{h}+\mathrm{S})$. Ở đây, $\mathrm{V}_{\max }$ là tốc độ tăng trưởng cực đại cố định của TVPD đồng thời cũng là tốc độ tiêu thụ dinh dưỡng cực đại của TVPD, $h$ là hằng số bán bão hòa.

Trong điều kiện dừng được giải với $\mathrm{dS} / \mathrm{dt}=0$ và $\mathrm{dX} / \mathrm{dt}=0$. Từ phương trình (1) và $(2)$, ta thu được hệ hai phương trình đại số (dấu * biểu thị các tham số ở trạng thái dừng):

$$
\begin{aligned}
& D\left(I-S^{*}\right)=\frac{V_{\max } S^{*} X^{*}}{\left(h+S^{*}\right)} \\
& \left(\frac{V_{\max } S^{*}}{\left(h+S^{*}\right.}-D\right) X^{*}=0
\end{aligned}
$$

Khảo sát trạng thái dừng của hệ (được giải với $\mathrm{dS} / \mathrm{dt}=0$ và $\mathrm{dX} / \mathrm{dt}=0$ ), ta có 3 trường hợp xảy ra khi $t \rightarrow \infty$.

Ở trạng thái dừng thứ 1 với $\mathrm{S}^{*}=0$ và $\mathrm{X}^{*}=$ 0 , tức là trạng thái khối nước không có TVPD và các chất dinh dưỡng, phương trình (3) sẽ không thỏa mãn vì $D \times I \neq 0$ bởi $D>0$ và $I>0$. Vì vậy, trạng thái này không tồn tại.

Ở trạng thái dừng thứ 2 với $\mathrm{S}^{*}=\mathrm{I}$ và $\mathrm{X}^{*}=0$ là trạng thái mà TVPD đã bị rửa trôi ra khỏi khối nước. Để trạng thái này tồn tại, bắt buộc tỉ lệ dòng ra $\mathrm{D}$ phải lớn hơn tốc độ phân chia tế bào riêng cực đại của TVPD, tức là $\mathrm{D}>\mathrm{V}_{\max } \mathrm{I} /(\mathrm{h}+\mathrm{I})$.

Cuối cùng, ở trạng thái dừng thứ 3 với $\mathrm{S}^{*} \neq$ 0 và $X^{*} \neq 0$, từ phương trình (4) ta có:

$$
\begin{aligned}
& S^{*}=\frac{\mathrm{Dh}}{\left(V_{\max }-D\right)} \\
& \text { Để } \mathrm{S}^{*}>0 \text { thì } \\
& V_{\text {max }}>\mathrm{D}
\end{aligned}
$$

Từ (3) và (4) ta cũng thu được phương trình $(7)$

$$
\begin{aligned}
& I=X^{*}+S^{*} \\
& \text { thay }(5) \text { vào }(7) \text { ta được } \\
& X^{*}=I-\frac{D h}{\left(V_{\max }-D\right)}
\end{aligned}
$$

Để $\mathrm{X}^{*}>0$ thì $\mathrm{I}>\mathrm{Dh} /\left(\mathrm{V}_{\max }-\mathrm{D}\right)$ và để duy trì điều kiện này thì $\mathrm{V}_{\max }$ phải thỏa mãn thêm điều kiện thứ hai, đó là

$$
V_{\text {max }}>\mathrm{D}(1+h / I)
$$

Điều này có nghĩa là, điều kiện (6) đảm bảo $\mathrm{S}^{*}>0$, nhưng không đảm bảo $\mathrm{S}^{*}<\mathrm{I}$. Nếu chỉ điều kiện (6) thỏa mãn thì khi $\mathrm{t} \rightarrow \infty$ hệ phương trình bắt đầu với $\mathrm{S}_{(\mathrm{t}=0)}=\mathrm{S}_{0}>0$ và $\mathrm{X}_{(\mathrm{t}=0)}=\mathrm{X}_{0}>0$ sẽ kết thúc ở $\mathrm{S}^{*}=\mathrm{I}$ và $\mathrm{X}^{*}=0$, tức là $\mathrm{TVPD}$ không tồn tại. Trường hợp này xảy ra khi khối lượng TVPD bị rửa trôi theo dòng ra $(\mathrm{D} \times \mathrm{X})$ lớn sự tăng trưởng của chúng $\left(\mathrm{V}_{\max } \mathrm{SX} /(\mathrm{h}+\mathrm{S})\right)$.

Vì vậy, để trạng thái dừng vẫn có TVPD tồn tại, yêu cầu phải có thêm điều kiện (9). Tuy nhiên việc kiểm soát tốc độ tiêu thụ dinh dưỡng cực đại của TVPD $\left(\mathrm{V}_{\max }\right)$ là không thể bởi nó phụ thuộc vào sinh khối TVPD có trong khối nước nên để cho hợp lý, điều kiện (9) được đổi thành điều kiện sau:

$$
I>\frac{D h}{\left(V_{\max }-D\right)}
$$

Điều kiện này cho thấy với việc kiểm soát hàm lượng dinh dưỡng được đưa vào khối nước, ta có thể hạn chế được sự tăng trưởng của sinh khối TVPD trong thủy vực.

Như vậy, nếu trong khối nước tồn tại các hoạt động nuôi thì lượng chất thải do các hoạt động này sinh ra sẽ góp phần làm gia tăng hàm lượng dinh dưỡng được đưa vào khối nước (DxI). Nhưng vì $\mathrm{D}$ không đổi nên sự gia tăng này chủ yếu nằm ở sự gia tăng nồng độ dinh dưỡng trung bình (I) của khối nước. Từ phương trình (5) ta thấy, kêt quả của sự gia tăng I không làm thay đổi hàm lượng dinh dưỡng tự nhiên của khối nước trong trạng thái dừng $\left(\mathrm{S}^{*}\right)$. Toàn bộ sự gia tăng này sẽ đi vào sinh khối TVPD khiến hàm lượng dinh dưỡng trong TVPD tăng lên đáng kể. Phương trình (7) cũng cho thấy, trong điều kiện dừng, sinh khối TVPD có mối tương quan tuyến tính với sự gia tăng của hàm lượng dinh dưỡng được đưa vào.

Giả sử, nếu hoạt động nuôi không tồn tại, từ phương trình (7) ta có

$$
I_{o}=X_{o}^{*}+S^{*}
$$

Trong đó $\mathrm{I}_{0}$ là hàm lượng dinh dưỡng từ các nguồn khác được đưa vào khối nước, kết qủa dẫn đển sinh khối nền TVPD trong khối nước $\mathrm{X}^{*}$.

Trường hợp nếu hoạt động nuôi tồn tại và phát thải một hàm lượng dinh dưỡng $I_{a}$ vào trong khối nước. Khi đó, phương trình (11) sẽ được viết lại như sau: 
$\left(I_{o}+I_{a}=\left(X_{o}^{*}+X_{a}^{*}\right)+S^{*}\right.$

Như vậy, sinh khối TVPD trong vực nước lúc này sẽ là $X^{*}+X^{*}$. Gọi $X^{*}{ }_{c}=X^{*}{ }_{0}^{*}+X^{*}$ và $X^{*}$ là ngưỡng giá trị cho phép đối với sinh khối TVPD trong khối nước, khi đó hàm lượng chất thải dinh dưỡng từ hoạt động nuôi tương ứng với giá trị này được xem là khả năng mang của vực nước $\left(\mathrm{I}_{\mathrm{c}}\right)$. Từ phương trình (12) suy ra:

$I_{c}=X_{c}^{*}+S^{*}-I_{o}$

nếu $X_{\mathrm{c}}^{*}$ lớn hơn $X_{\mathrm{o}}$ thì ta có $\mathrm{I}_{\mathrm{c}}>0$.

Tuy nhiên, vì TVPD tiêu thụ hết nguồn dinh dưỡng gia tăng từ hoạt động nuôi bởi $S^{*}$ không đổi khi $\mathrm{I}$ tăng nên $\mathrm{X}_{\mathrm{c}}^{*}$ có thể lớn hơn rất nhiều $\mathrm{S}^{*}$. Do đó, có thể loại bỏ $\mathrm{S}^{*}$ trong phương trình (13) thành phương trình có dạng xấp xỉ sau:

$$
I_{c}=X_{c}^{*}-I_{o}
$$

\section{2. Ước tính tỉ lệ trao đổi nước}

Đối với các vũng vịnh nước nông ven bờ có diện tích nhỏ, địa hình đáy đơn giản không chịu tác động của dòng chảy sông, có thể áp dụng cách tính thời gian trao đổi nước theo phương pháp thấu kính triều.

Theo cách tiếp cận này, một khối nước được giả thiết là có sự xáo trộn mạnh, ảnh hưởng của dòng chảy sông không đáng kể so với dòng triều sẽ có thời gian trao đổi nước $\left(\mathrm{T}_{\mathrm{f}}\right)$ được ước tính như sau:

$$
T_{f}=\frac{V T}{(1-b) P_{t}}
$$

Trong đó, $\mathrm{V}$ là thể tích trung bình của khối nước; $\mathrm{T}$ là chu kỳ triều; $\mathrm{P}_{\mathrm{t}}$ là thể tích thấu kính triều $-\mathrm{P}_{\mathrm{t}}$ có thể được ước tính từ diện tích mặt nước ở mực nước biển trung bình $(\mathrm{S})$ với biền độ triều $(\mathrm{R})$ theo công thức $\mathrm{P}_{\mathrm{t}}=\mathrm{S} \times \mathrm{R}$; $\mathrm{b}$ là hệ số dòng quay trở lại, giá trị của $\mathrm{b}$ dao động từ 0,0 đến 1,0 . Do $b$ phụ thuộc vào hoạt động của dòng ra khi rời khỏi khối nước nên giá trị của $b$ không phụ thuộc vào các thông số hình thái của khu vực. Việc ước tính $\mathrm{b}$ có thể được thực hiện bằng phương pháp tính toán với các nghiên cứu về dòng triều và dòng chảy bên ngoài khối nước nhưng cũng có thể bằng việc lựa chọn một hệ số thích hợp khi thiếu các điều kiện trên. Vì vậy, trong phạm vi nghiên cứu này, để thuận tiện cho việc tính toán, $\mathrm{b}$ được chọn với các giá trị là 0,$2 ; 0,5$ và 0,7 ứng với các mức khảo sát tỉ lệ dòng quay trở lại nhỏ, trung bình và lớn.

\subsection{Các vấn đề và điều kiện áp dụng}

Có 4 vấn đề cần phải xem xét khi áp dụng các phương pháp trên.

- Vấn đề thứ 1 là việc lựa chọn yếu tố nào sẽ là yếu tố dinh dưỡng hạn chế sự tăng trưởng của TVPD trong khối nước. Nếu lấy các yếu tố đã có nồng độ cao hơn nhiều so với nồng độ mà TVPD cần cho tăng trưởng thì việc áp dụng phương trình (14) sẽ cho khả năng mang nhỏ hơn so với thực tế. Vì vậy để tận dụng các kết quả nêu trên, yếu tố dinh dưỡng có tỉ lệ nhỏ hơn so với các yếu tố khác trong khối nước sẽ được lựa chọn.

Nhìn chung, các vực nước đang chịu tác động từ hoạt động nuôi trồng đều bị ảnh hưởng của các chất thải dinh dưỡng. Trong đó, điển hình là ni tơ $(\mathrm{N})$ và phốt pho $(\mathrm{P})$, so với $\mathrm{N}$ lượng $\mathrm{P}$ thải ra từ hoạt động nuôi thường nhỏ hơn rất nhiều. Kết quả ước tính lượng phát thải $\mathrm{N}$ và $\mathrm{P}$ từ hoạt động nuôi trong vùng nghiên cứu năm 2016 cũng cho thấy xu hướng đó [6]. Tuy nhiên theo Smith (1982) đây cũng là hai yếu tố dinh dưỡng thiết yếu cần cho sự tăng trưởng của TVPD. Khi nghiên cứu về mối tương quan giữa TVPD với $\mathrm{N}, \mathrm{P}$ thông qua hàm lượng Chl-a tại các vùng nước ven bờ Florida (với hơn 300 trạm thu mẫu), Hoyervà các cộng sự (2002) đã chỉ ra rằng $\mathrm{P}$ giải thích tới $81 \%$ $\left(\mathrm{R}^{2}=0.81\right)$ sự biến đổi của hàm lượng Chl-a trong khi $\mathrm{N}$ chỉ giải thích khoảng $41 \%\left(\mathrm{R}^{2}=\right.$ 0.41 ) về sự biến đổi này. Theo đó, phương trình biểu diễn mối tương quan giữa $\mathrm{Chl}-\mathrm{a}$ và $\mathrm{P}$ được xác định như sau [7]:

$$
\log _{10}(\mu g C h l-a / L)=-1,134+1,17 \log _{10}(\mu g P / L)
$$

Trước đó, Redfield (1958) đã nhấn mạnh đến vai trò của $\mathrm{P}$ như là một yếu tố chính hạn chế sự tăng trưởng của quần xã TVPD trong nghiên cứu của mình và Heckey, Kilham (1998) cũng cho rằng $\mathrm{P}$ kiểm soát sinh khối TVPD trong nhiều hệ thống nước ngọt và điều này cũng phù hợp với sinh lý và nhu cầu dinh 
dưỡng đối với TVPD trong các hệ thống nước biển ven bờ.

Vì vậy, trong phần ứng dụng, $\mathrm{P}$ được lựa chọn là yếu tố dinh dưỡng hạn chế.

- Vấn đề thứ 2 liên quan đến lượng phát thải $\mathrm{P}$ vì $\mathrm{P}$ quyết định hàm lượng dinh dưỡng của khối nước khi có mặt các hoạt động nuôi $\left(\mathrm{I}_{\mathrm{c}}\right)$ theo công thức:

$$
I_{c}=\frac{F_{n}}{D V}
$$

(trong đó, $\mathrm{F}_{\mathrm{n}}$ là lượng $\mathrm{P}$ phát thải từ hoạt động nuôi) nên $\mathrm{P}$ phải được ước tính. Trong phần ứng dụng của phương pháp này, $\mathrm{P}$ được ước tính dựa trên phương pháp cân bằng vật chất giữa cá và hệ thống nuôi trồng [6].

- Vấn đề thứ 3 là giá trị hàm lượng Chl-a cho phép hay giá trị Chl-a tiêu chuẩn. Đây là một giá trị bắt buộc, nó được dùng để làm tiêu chuẩn so sánh với hàm lượng $\mathrm{Chl}-\mathrm{a}$ tính được. Nhưng vì giá trị này chưa có trong danh mục tiêu chuẩn Việt Nam đối với nước biển ven bờ nên tác giả đã tham khảo giá trị Chl-a tiêu chuẩn của Tổ chức bảo vệ Môi trường Hoa Kỳ (USEPA).Theo đó, giá trị Chl-a tiêu chuẩn là $12,35 \mu \mathrm{g} / \mathrm{L}$.

- Vấn đề thứ 4 liên quan đến hàm lượng dinh dưỡng nền của khối nước $\left(\mathrm{I}_{0}\right)$, tức hàm lượng dinh dưỡng được cung cấp từ những nguồn khác (ngoài nguồn phát thải từ hoạt động nuôi) như sông suối, ao hồ hay nước thải,...Việc ước tính gần đúng hàm lượng này có thể được thực hiện bằng đo đạc hoặc tính toán. Tuy nhiên, với các vực nước đang chịu tác động chính của hoạt động nuôi lại ít sông suối đổ vào thì hàm lượng này có thể bỏ qua do hàm lượng dinh dưỡng từ nuôi trồng luôn chiếm ưu thế.

Cuối cùng, có 4 điều kiện chung để khối nước đang xét có thể áp dụng các phương pháp ước tính trên, đó là:
(1) Khối nước đang xét phải có sự xáo trộn tốt.

(2) Khối nước đang xét chịu ảnh hưởng mạnh của dòng triều.

(3) Khối nước đang xét phải có vùng nước bên ngoài đủ lớn để có thể pha loãng lượng vật chất trong vịnh đi ra mà không bị ảnh hưởng ô nhiễm ngược bởi các vật chất đó.

(4) Khối nước đang xét chấp nhận giả thiết khối lượng dòng ra bằng khối lượng dòng vào.

\section{Kết quả ứng dụng}

Như đã giới thiệu ở phần mở đầu, Bến Bèo là khu vực vịnh nước nông có diện tích nhỏ và khá kín nên có thể áp dụng giả thiết nước trong vịnh có sự xáo trộn tốt. Hơn nữa, theo số liệu quan trắc hàng năm, độ muối trong khu vực luôn dao động ở ngưỡng 28-30\%o [1], vì vậy ảnh hưởng của nước ngọt gần như không đáng kể. Vịnh có hai cửa thông với vùng nước bên ngoài. Cửa phía đông hẹp hơn (rộng khoảng 3$4 \mathrm{~km}$ ) thông ra vịnh Lan Hạ có diện tích khoảng $33 \mathrm{~km}^{2}$, cửa phía nam rộng hơn khoảng trên $6 \mathrm{~km}$ thông ra biển Đông (hình 1).

Đây là khu vực mang đặc điểm chung của thủy triều Vịnh Bắc Bộ, thuộc loại nhật triều đều nhưng chậm pha hơn ở Hòn Dấu từ 20 - 30 phút. Kết quả thống kê độ cao mực nước tại Hòn Dấu trong bảng thủy triều 3 năm gần đây $(2016,2017$ và 2018$)$ [8] cho thấy khoảng $2 / 3$ thời gian các ngày trong năm biên độ triều dao động ở mức 1,6 - 2.9m. Khoảng thời gian còn lại là các giá trị biên độ ở mức thấp hơn và cao hơn. Trong đó, biên độ triều lớn hơn hoặc bằng $3 \mathrm{~m}$ chỉ chiếm vài chục ngày trong năm. Vì vậy, ở đây hai giá trị biên độ triều trung bình là $1,8 \mathrm{~m}$ và biên độ triều cực đại là $3 \mathrm{~m}$ đã dược sử dụng để tính toán tỉ lệ trao đổi nước khu vực nghiên cứu. Kết quả thể hiện ở bảng 1 .

Bảng 1. Tỉ lệ trao đổi nước khu vực vịnh Bến Bèo

\begin{tabular}{ccccccc}
\hline Biên độ triều $(\mathrm{m})$ & \multicolumn{3}{c}{$1,8 \mathrm{~m}$} \\
\hline Hệ số dòng & 0,7 & 0,5 & 0,3 & 0,7 & 0,5 & 0,3 \\
Tỉ lệ trao đổi nước & 0,016 & 0,027 & 0,038 & 0,046 & 0,077 & 0,18 \\
\hline
\end{tabular}




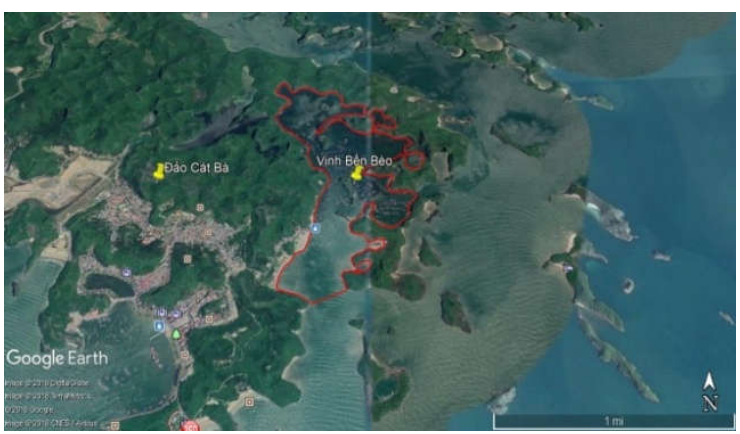

Hình 1. Ảnh vệ tinh khu vực nghiên cứu.

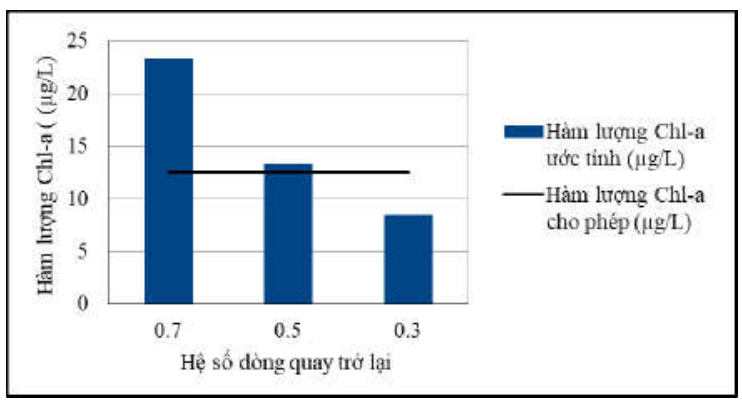

Hình 2. Kết quả ước tính hàm lượng Chl-a năm 2017 (trong điều kiện biên độ triều trung bình).

Các kết quả ước tính từ hoạt động nuôi 2017 cho thấy, mỗi ngày khu vực vịnh phải tiếp nhận khoảng 98,7kgP từ hoạt động nuôi. Ở điều kiện biên độ triều trung bình, lượng phát thải này dẫn đến sự gia tăng của sinh khối TVPD vượt ngưỡng cho phép khi tỉ lệ trao đổi nước yếu đến trung bình (hình 2).

Trong trường hợp nếu tính thêm lượng dinh dưỡng được đưa vào từ các nguồn khác và giả sử lượng này bằng $1 / 3$ lượng phát thải từ hoạt động nuôi thì mức độ an toàn đối với số lượng cá nuôi đang tồn tại không được đảm bảo bởi các giá trị nồng độ Chl-a tương ứng đều xấp xỉ hoặc vượt mức giới hạn cho phép (hình 3 ).

Ở điều kiện biên độ triều lớn, tỉ lệ trao đổi nước cũng tăng lên đáng kể. Do vậy, với cùng lượng chất thải nuôi, giá trị hàm lượng $\mathrm{Chl}-\mathrm{a}$ tương ứng đều thấp hơn so với ngưỡng cho phép (hình 4), thậm chí kể cả khi lượng chất thải dinh dưỡng tăng thêm gấp rưỡi, tức là khi có thêm lượng dinh dưỡng từ các nguồn khác bằng $1 / 2$ (hình 5 ).

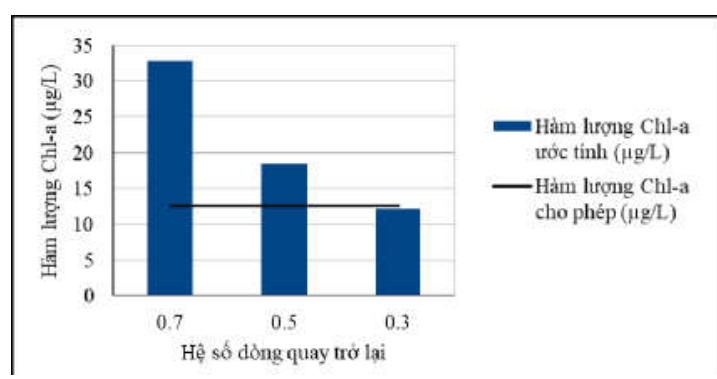

Hình 3. Kết quả ước tính hàm lượng Chl-a năm 2017 khi lượng dinh dưỡng tăng thêm $1 / 3$ (trong điều kiện biên độ triều trung bình).

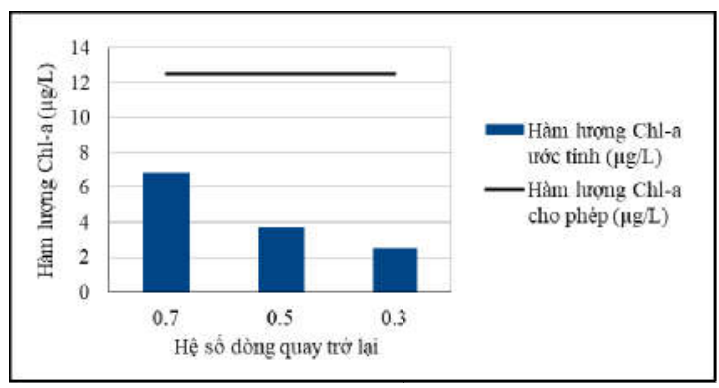

Hình 4. Kết quả ước tính hàm lượng Chl-a năm 2017 (trong điều kiện biên độ triều lớn).

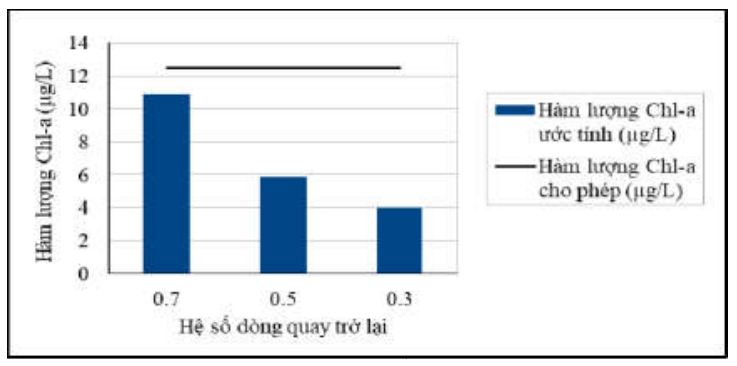

Hình 5. Kết quả ước tính hàm lượng Chl-a năm 2017 khi lượng dinh dưỡng tăng thêm $1 / 2$ (trong điều kiện biên độ triều lớn).

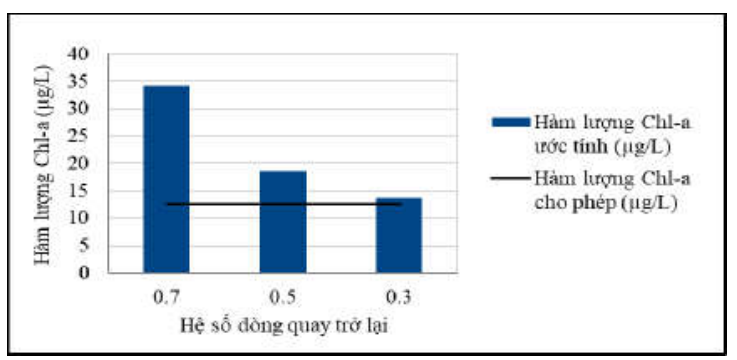

Hình 6. Kết quả ước tính hàm lượng Chl-a năm 2008 (trong điều kiện biên độ triều trung bình). 


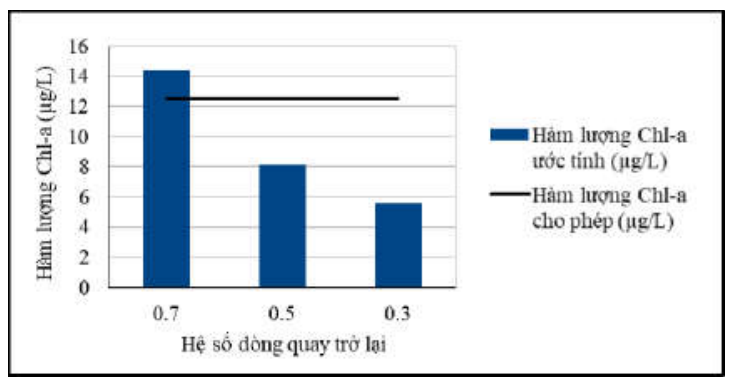

Hình 7. Kết quả ước tính hàm lượng Chl-a năm 2008 khi lượng dinh dưỡng tăng thêm $1 / 3$ (trong điều kiện biên độ triều lớn).

Các kết quả ước tính từ hoạt động nuôi năm 2008 (là năm có hiện tượng cá nuôi chết hàng loạt) cho thấy do mật độ lồng nuôi lớn, lượng phát thải dinh dưỡng từ hoạt động nuôi cũng rất lớn. Theo ước tính, lượng này là $136,3 \mathrm{kgP} / \mathrm{ngày}$. Tương ứng với điều kiện môi trường ở các mức trao đổi nước khác nhau với cùng điều kiện biên độ triều trung bình, hàm lượng Chl-a phát sinh từ chất thải nuôi luôn vượt ngưỡng cho phép (hình 6), tức là luôn vượt quá khả năng mang của khu vực.

Nhưng với điều kiện biên độ triều lớn, lượng phát thải này vẫn nằm trong khả năng mang của khu vực. Tuy nhiên, nếu cộng thêm lượng dinh dưỡng từ các nguồn khác với hàm lượng giả thiết bằng $1 / 3$ thì hàm lượng $\mathrm{Chl}-\mathrm{a}$ tương ứng sẽ vượt mức chịu tải khi tỉ lệ trao đổi nước quá nhỏ (hình 7).

Các kết quả ước tính theo quy hoạch đến năm 2020 cho thấy, với số lồng nuôi giảm còn 2.720 ô lồng, sản lượng trung bình $270-320 \mathrm{~kg} /$ ô lồng, mỗi ngày lượng chất thải tương ứng được đưa vào vực nước sẽ lần lượt là $51,8 \mathrm{kgP} /$ ngày là $50,3 \mathrm{kgP} / \mathrm{ngày}$. Tương ứng với lượng chất thải này, giá trị hàm lượng Chl-a ở mức cao nhất (trong điều kiện biên độ triều trung bình và hệ số dòng quay trở lại lớn) cũng chỉ đạt $11 \mu \mathrm{gChl}-\mathrm{a} / \mathrm{L}$ tức là vẫn dưới giới hạn cho phép.

Như vậy, trong điều kiện biên độ triều lớn, khả năng mang của môi trường cũng lớn hơn. Nếu tỉ lệ trao đổi nước tốt, môi trường càng có khả năng chịu tải tốt. Nhưng những điều kiện này không tồn tại thường xuyên, số lượng ngày có biên độ triều lớn chỉ dao động từ 25 - 35 ngày trong năm. Các ngày còn lại phổ biến ở biên độ triều trung bình nên các kết quả tính trong điều kiện này gần với thực tế hơn.

Tuy nhiên, nếu biên độ triều quá nhỏ, nhất là vào các thời kỳ triều kém, khả năng mang của khu vực sẽ bị hạn chế. Khi đó, chỉ riêng chất thải từ hoạt động nuôi, kể cả trong trường hợp quy hoạch cũng vượt quá sức tải của khu vực.

\section{Kết luận}

Khả năng mang đối với hoạt động nuôi trồng của một khối nước có thể được tính toán dựa trên hàm lượng dinh dưỡng phát thải từ hoạt động nuôi (hoặc bao gồm cả các nguồn bên ngoài), tỉ lệ trao đổi nước và nguy cơ bùng phát của tảo.

Với các giả thiết và điều kiện yêu cầu để giải các phương trình, phương pháp ước tính được đề cập rất phù hợp cho việc đánh giá sức tải môi trường của các vịnh triều nhỏ, nước nông ven bờ như vịnh Bến Bèo.

Các kết quả ứng dụng cho thấy khu vực nghiên cứu đang có dấu hiệu bị đe dọa bởi hoạt động nuôi nếu số lượng lồng nuôi vẫn tiếp tục duy trì như năm 2017.

Với số lượng lồng nuôi phát triển như năm 2008, khả năng mang của môi trường bị quá tải rất lớn và hậu quả đã được kiểm chứng trên thực tế.

Những ước tính trên cơ sở quy hoạch cho thấy, sản lượng nuôi và số lồng nuôi theo dự kiến đều nằm trong ngưỡng an toàn của môi trường.

\section{Tài liệu tham khảo}

[1] Số liệu quan trắc hàng năm khu vực biển quanh đảo Cát Bà do Trung tâm quan trắc môi trường Biển, Viện Hải sản thực hiện.

[2] Sở VHTTDL Hải phòng (2010), Báo cáo: Quy hoạch tổng thể phát triển du lịch bền vững quần đảo Cát Bà đến năm 2025, tầm nhìn đến năm 2050. 
[3] UBND huyện Cát Hải (2008). Báo cáo đánh giá thực trạng phát triển nuôi cá lồng bè trên vịnh Cát Bà, Hải Phòng.

[4] Sở Nông nghiệp và Phát triển nông thôn Hải Phòng (2010), Đề án: Quy hoạch chi tiết phát triển nuôi trồng hải sản trên vùng biển Hải Phòng đến năm 2015, định hướng đến năm 2020.

[5] Legović Tarzan; Palerud Rune; Christensen Guttorm; White Patrick; Regpala, Regie (2008), A model to estimate aquaculture carrying capacity in three areas of the Philippines, Science Diliman (0115-7809) Vol. 20, p.31-40.

[6] Trịnh Thị Lê Hà, Đoàn Văn Bộ (2016), Ước tính lượng phát thải dinh dưỡng từ hoạt động nuôi cá lồng tại vịnh Bến Bèo, Cát Bà, Hải Phòng, Tạp chí Khoa học ĐHQGHN: Các Khoa học Trái đất và Môi trường, Tập 32, Số $3 \mathrm{~S}$, tr. 77-82.

[7] Hoyer M. V.; Frazer T. K.; Notestein S. K.; Canfield D. E. (2002), Nutrient, chlorophyll, and water clarity relationships in Florida's nearshore coastal waters with comparisons to freshwater lakes, Canada Journal of Fisheries and Aquatic Sciences 59, p. 1024-1031.

[8] Tổng cục Biển và Hải đảo Việt Nam, Trung tâm Hải văn, Bảng thủy triều 2016, 2017, 2018, tập 1, Nhà xuất bản khoa học tự nhiên và công nghệ.

\title{
Model of Estimating the Aquaculture Carrying Capacity for Shallow-Water Tidal Embayments; Model Application to Ben Beo bay, Cat Ba Island, Hai Phong
}

\author{
Trinh Thi Le Ha \\ Faculty of Hydro-Meteorology and Oceanography, VNU Hanoi University of Science, \\ 334 Nguyen Trai, Thanh Xuan, Hanoi, Vietnam
}

\begin{abstract}
Model was developed to estimate the production carrying capacity of water bodies based on nutrient inputs from aquacultures, flushing rates and the risk of algal blooms for ShallowWater Tidal Embayments. Model was applied to Ben Beo bay, Cat Ba Island, Hai Phong. The results suggest that nutrient loadings from cage-culture practices in 2017 were greater than the carrying capacity of Ben Beo during low and average tidal exchange. The emission of nutrients by fish cultures in 2008 into water body was greater than the sustainable carrying capacity. The aquaculture production in Plan has not overcome Ben Beo's carrying capacity even during low tidal exchange. However, during neap tide, carrying capacity has been able to overcome.
\end{abstract}

Keywords: Carrying capacity, nutrient, aquacultures. 